\title{
Evaluación de programas educativos que abordan los procesos de patrimonialización
} Evaluation Of Educational Programs
Concerned On Heritagization Processes

\author{
Olaia Fontal Merillas \\ Carmen Gómez-Redondo
}

Universidad de Valladolid

Resumen: Partimos de una conceptualización de los procesos de patrimonialización a partir de las tres agencias diferentes que participan de los mismos: institucional, individual y comunitaria. Esto nos permite abordar los procesos de legitimación, identización y creación cultural, hasta determinar una secuencia procedimental que desvela las fases de los procesos de patrimonialización que, posteriormente, serán empleados desde el Observatorio de Educación Patrimonial en España (OEPE), para el inventario, análisis y evaluación de distintos programas educativos. Finalmente, proponemos el análisis de tres ejemplos referentes que nos permitirán detectar e inferir características de los modelos de educación patrimonial atendiendo a las agencias que los proponen.

Palabrasclave: Educación patrimonial, patrimonio cultural, procesos de patrimonialización, procesos de identización, evaluación de programas educativos.

Abstract: We start from a conceptualization of the heritagization processes having account the three different agencies involved in them: institutional, individual and community ones. This allows us to manage the processes of legitimation, identization and cultural creation, in order to determine a procedural sequence which reveals the phases of the heritagization processes that, subsequently, will be used from the Spanish Heritage Education Observatory, SHEO for inventory, analysis and evaluation of various educational programs. Finally, we propose the analysis of three leading examples which will allow us to detect and to infer characteristics of the models of heritage education as an answer to the proposed agency.

Keywords: Heritage Education, Cultural Heritage, Heritagization Processes, Identization Processes, evaluation of educational programs.

(Fecha de recepción: octubre, 2014, y de aceptación: febrero, 2015)

DOI: 10.7203/DCES.29.3960

\footnotetext{
*Este artículo, así como la información contenida en él, procede de las investigaciones realizadas en el seno del proyecto de I+D+i "Educación Patrimonial en España: Evaluación de programas, consolidación e internacionalización del Observatorio de Educación Patrimonial en España (OEPE)” (Ref: EDU201237212), financiado por el Ministerio de Economía y Competitividad (Enero de 2013-Diciembre de 2015), cuya IP es la Dra. Fontal.
} 


\section{Introducción}

El proceso de patrimonialización se dibuja en el ámbito dinámico y dialéctico en el que se embebe y construye la propia cultura. Como parte de este sistema, existe también una dimensión individual y una colectiva, por tanto una subjetivación y una objetivación simultáneas, constantes (Fontal, 2003). Dicho proceso se configura en relación con los diferentes agentes que lo producen, en el entorno y medios que lo construyen (Pérez, 2013); por tanto, a la vez que un proceso se construye un producto, no tanto material, sino como un nodo cultural, como un conjunto de normas, conductas, creencias y actitudes que se desarrollan y cobran sentido en el entorno patrimonial. De este modo, los procesos establecidos, tanto desde la institución como desde la comunidad, desde la sociedad y desde el individuo, conducen a la patrimonialización y, por tanto, construyen patrimonios que se entretejen, dando lugar a un proceso cultural o, en tanto en cuanto prevalece como objetivación por encima de la práctica cultural, un proceso metacultural, que trenza los diversos procesos, otorgándoles sentido en este contexto específico (Gómez, 2012).

La acción educativa se sitúa como elemento clave en estos procesos de patrimonialización y su posterior identización, en tanto permite la apropiación simbólica del patrimonio, así como la toma de conciencia de su valor identitario. Algunos programas en educación patrimonial sitúan precisamente los procesos de patrimonialización e iden- tización como objetivos clave o procedimientos metodológicos estructurales. Así pues, a través de este artículo se pretende, por medio de la investigación evaluativa, conocer en profundidad la significatividad de la acción educativa en estos procesos.

\section{Enfoque cultural de los procesos de patrimonialización: legitimación, identización y creación cultural}

Consideramos el patrimonio no solo como acervo de materiales, sino como un complejo de vínculos y relaciones entre los individuos y algunas construcciones de su propia cultura, ya sean materiales o simbólicas. Podríamos decir, entonces, que patrimonio refiere a un campo semántico, una serie de objetos, procesos, normas, valores, actitudes... que se relacionan en torno a la idea de herencia -tanto la recibida como la producida con intención de dejar legado-. De este modo, únicamente se consideran patrimonio aquellos bienes culturales que han pasado por lo que denominamos proceso de patrimonialización. Esto significa que para que esa parte de la cultura se convierta en patrimonio, debe haber experimentado un proceso -largo y complejo- de adhesión por parte de determinados individuos o grupos (Fontal, 2004, p.17). Hablamos de lo patrimonial o patrimoniable como aquello que es susceptible de ser patrimonio, una vez ha pasado a integrarse en el conjunto de referentes culturales de determinado individuo o grupo. 
Por eso, el patrimonio -en tanto construcción cultural- toma la forma dialógica y dinámica de ésta. De este modo, hablamos de "construcción de patrimonio" como un proceso que además concierne a todos los niveles a los que afecta la cultura, es decir, se construye patrimonio tanto en lo objetual como en lo simbólico, y sus agentes son todos los miembros de la cultura en tanto asuman diferentes roles (colectivo concreto, colectivo abstracto, individual). Esto implica considerar los procesos de patrimonialización en, al menos, tres niveles o dimensiones que son parte de un complejo proceso cultural que sucede simultánea y entrelazadamente -institucional, cultural y comunitario- y que derivan en la legitimación, identización y creación cultural.

\section{Ladimensión institucional:legitimación}

Uno de los grandes agentes de construcción del patrimonio es el colectivo, entendido de manera estructurada, es decir, la institución. Ésta es comprendida como personificación abstracta compuesta por cierto número de personas que no actúan como tales en la toma de decisiones sino que se atienen al cumplimiento de normas, costumbres, valores, etcétera que han sido consolidados como los fundamentos de dicha institución.

Es posible hablar de este proceso como una serie de universos simbólicos legitimados (Berger y Luckman, 1968), de modo que el patrimonio se configura como conjunto de significados legitimados por la institución. Desde la abstrac- ción subjetiva, la institución selecciona lo que finalmente se configurará como patrimonio, como significado cultural que debe ser enculturador. Desde este punto de vista podría decirse que sin poder, no existe patrimonio (Prats, 2004, p.35).

Generalmente el patrimonio legitimado desde estas instituciones es construido en base a valores que refieren a su historicidad, es decir, a la perpetuación de la institucionalidad a lo largo de la historia (LLull, 2005). Se valora mirando hacia el pasado, lo que supone legitimaciones en base a paradigmas patrimoniales estáticos y premodernos. En ocasiones, las instituciones, al amparo de una idea estática de los valores culturales, no resultan permeables a las dinámicas sociales y terminan por convertir la legitimidad que les otorga el propio sistema cultural en un instrumento de poder para la imposición de sus criterios, muchas veces derivados de criterios expertos (Aguirre, 2008, p. 95). En estos casos, se produce un canal que se perfila impermeable a las interpretaciones y selecciones de los individuos, dejando a éstos al margen de su empleo y significación. La salida a los procesos de socialización vinculados al patrimonio, -o dicho de otro modo, los procesos por los cuales las instituciones hacen partícipes de este patrimonio a los ciudadanos-, se remite en su mayoría a la educación, vista dentro de una gestión integrada del patrimonio cultural (Fontal y Juanola, 2015).

Así, por ejemplo, la legislación Estatal sobre patrimonio -que comprende 
inmuebles y objetos muebles de interés artístico, histórico, paleontológico, arqueológico, etnográfico, científico o técnico (...) el patrimonio documental y bibliográfico, los yacimientos y zonas arqueológicas, así como los sitios naturales, jardines y parques que tengan valor artístico, histórico o antropológico (BOE, 29/06/1985)-, para operar con todos estos bienes, apuesta por una gestión integral que comprende la intervención educativa. De este modo, se supera la mentalidad de mantenimiento del bien en su dimensión histórica, tangible, y se busca no tanto declarar la necesidad de protección como educar a la sociedad para que ésta sea quien reclame dicha necesidad de custodia y cuidado. En este sentido, la Ley 16/1985 de Patrimonio Histórico Español pone el acento en el valor del patrimonio como elemento de identidad cultural, incluso considerando qué bienes de entre los que lo integran se han convertido en patrimoniales, atendiendo sobre todo a su función social. Así es como se entiende que el patrimonio ha de estar al servicio de la colectividad porque, con su disfrute, se facilita el acceso a la cultura (BOE, 19/07/1985).

Desde un enfoque institucional, patrimonializar supone construir un patrimonio, no tanto en la dotación de fisicidad como en la atribución de significados. Hablamos de un patrimonio que aparece como resultado de un proceso de significación particular, exclusivo, erudito y aportado desde una visión especializada. Este tipo de patrimonio no se refiere únicamente a normativas estatales sino que, antes, ya queda definido por organismos internacionales como UNESCO. Pero además, los textos institucionales, redactados en las diferentes convenciones internacionales, tratados, acuerdos e incluso leyes sobre el patrimonio, resultan en ocasiones una fuente de definiciones que nos sirven para pensar el patrimonio desde un enfoque actualizado y con visión de futuro. Así, por ejemplo, en la Convención para la Salvaguarda del Patrimonio Cultural Inmaterial, se reivindica que el patrimonio cultural no se limite a monumentos y colecciones de objetos, sino que comprenda también tradiciones o expresiones vivas heredadas de nuestros antepasados y transmitidas a nuestros descendientes, como tradiciones orales, artes del espectáculo, usos sociales, rituales, actos festivos, conocimientos, prácticas, saberes y técnicas vinculados a la artesanía tradicional (UNESCO, 2003).

Sin duda, esta definición de patrimonio cultural -que resalta los elementos inmateriales- puede considerarse uno de los grandes aportes del siglo XXI, en tanto que aleja el concepto de patrimonio de una visión materialista que rinde culto al objeto e incorpora lo inmaterial no tanto como un subtipo de patrimonio, sino como una dimensión esencial de todo bien patrimonial; así, lo inmaterial pasa de ser un elemento periférico, a convertirse en una dimensión clave para conceptualizar lo patrimonial (Fontal, 2013). Ambos ejemplos, el de la normativa estatal y el de la regulación internacional, nos pueden ayudar en la 
comprensión de los procesos de patrimonialización institucional, dejando entrever una visión que alude a un discurso inferido del pasado, en tanto en cuanto es posible hablar de un valor de historicidad, ya sea derivada de bienes materiales o inmateriales. Para comprender y significar este patrimonio, el proceso de patrimonialización se centra en legitimar los significados del contexto original.

El producto resultante de este proceso es lo que Fontal define como un sedimento de la parcela cultural (Fontal, 2003), es decir, el acervo patrimonial como el conjunto de bienes que han sido perpetuados históricamente. De este modo, podemos entender el patrimonio como un residuo significante que cada momento cultural ha ido depositando y que, en determinado momento, puede servir como indicio para reconstruir ese pasado cultural (Fontal, 2003, p. 38).

Esta valoración del patrimonio como sedimento de la cultura que debe ser transmitido para no ser perdido, puede excluir en gran parte la visión subjetiva de los individuos que conforman la cultura y sociedad en el presente. Sucede así cuando un individuo, colectivo o comunidad no encuentran en el patrimonio institucionalizado respuestas a su entorno, no consiguen dotarlo de sentido hoy, porque sus significados están contextualizados en un pasado con el que se mantienen escasos vínculos. Esto supone que, en numerosas ocasiones, pese a las labores de conservación de la institución, los individuos, como agentes culturales no se apropien simbólicamente del patrimonio.

Nuevamente, recae en la educación la finalidad de recontextualizar, de resignificar. En esta concepción del patrimonio como sedimento, la mediación que se establece por la institución legitimadora guiará sus pasos hacia viajes en el tiempo, de modo que los individuos se sumarán a esta legitimación de significados pasados para poder comprender el bien en su contexto, aprender su significado y así garantizar su conservación. Dicho de otro modo, el individuo, grupo o comunidad, convertidos en agentes legitimadores, reafirman la idea de continuidad del sustrato que los sitúa en el devenir histórico; a través de la significación del pasado, confirman su existencia en el presente, y al legitimar dan una continuidad histórica a la que ya pertenecen. Podríamos decir, por tanto, que la institucionalización del patrimonio aporta de manera positiva un hilo de continuidad temporal que ayuda al individuo, grupo, comunidad y sociedad, en general, a definirse en el tiempo respecto a un pasado del que forman parte en realidad (Ballart, 1997, p.36).

\section{La dimensión cultural: identización}

Otro de los agentes que interviene -en solitario o agrupado- en el proceso de patrimonialización como agente significador es el individuo, que se dibuja a través de las relaciones con el entorno y se conforma de múltiples identidades individuales e individualizadas desde 
la colectividad. Hablamos de identización, de una discusión y “discursión” del individuo y el entorno; de este modo, en el encuentro y desencuentro con la otredad aparecen las diferentes pertenencias y propiedades simbólicas (GómezRedondo, 2013).

Nos referimos a significados que conectan a los individuos con sus patrimonios, alejándonos de los significados "verdaderos" y "unívocos" para aproximarnos a significados consensuados o construidos por el grupo. El patrimonio se configura como seña identitaria de un colectivo y esto ocurre a través del consenso, que permite que los significados atribuidos al patrimonio sean más dinámicos, cambiando según las variaciones de la cultura (Prats, 2004, p.61-62).

De este modo, el proceso de patrimonialización que se perpetúa desde esta agencia se realiza a través de la atribución de significados. Sin embargo, a diferencia del caso anterior, el bien patrimonial tiene valor de contemporaneidad, los nuevos significados atribuidos ayudan a los individuos a dotar de sentido a su entorno presente. El individuo, por tanto, no aprende significados, sino que los atribuye desde su experiencia y desde el sentido que tiene su entorno; la patrimonialización cultural contextualiza al bien en el presente.

El proceso de patrimonialización pasa primero por una apropiación simbólica del individuo, lo que definiríamos como "patrimonios personales", que conforman el universo identitario referencial del éste. El individuo genera una serie de relaciones cognitivas y socioafectivas con el potencial bien, lo que al convertirlo en propiedad significativa en cuanto a su capacidad de definición de dicho individuo, se torna en patrimonio real, aprehendido, apropiado.

Por tanto, el proceso de patrimonialización a nivel individual refiere a la construcción de significados en torno a la propiedad simbólica. Esta propiedad adquiere mayor significación al revelarse su valor de identización, es decir, ayuda al individuo a construir su identidad.

A medida que se asciende hacia capas más exteriores en el círculo de identidades, estas propiedades simbólicas y sus significados son cada vez compartidos por mayor número de personas. Estos bienes se configuran como patrimonios compartidos que, a través del consenso, se asumen como comunes, por tanto colectivos.

Por tanto, la patrimonialización cultural tiene efectividad a dos niveles, por un lado individual, donde se subjetiva y dota de significados personales, se generan relaciones y vínculos asociados a la propia historia e identidad; hablamos de una patrimonialización desde el interior de la cultura. En un segundo nivel, la patrimonialización consiste en encontrar similitud, configurar una comunidad frente a la otredad, por tanto la patrimonialización es significación consensuada, configura al bien patrimonial como vínculo, entre los individuos con el objeto. El patrimonio construido a partir de esta patrimonia- 
lización puede considerarse como una "seña de identidad".

\section{La dimensión comunitaria: creación}

Esta última dimensión enfoca la patrimonialización desde el punto de vista de la comunidad, se acerca a la creación autónoma y sin directrices del propio acervo patrimonial. En este caso ya no se busca únicamente acercar a la población los bienes culturales para su consumo, sino favorecer que la gente configure por sí misma su acervo cultural, mediante el aprendizaje significativo y la recuperación de los signos de identidad que definen a cada sociedad (LLull, 2005, p.199).

Consideramos que una de las aportaciones desde la educación patrimonial en el s. XXI es plantear los procesos de patrimonialización desde una apropiación simbólica centrada en la creación, en tanto crea vínculos y actitudes patrimoniales. Así pues, referimos a una agencia activa, educada, consciente de su capacidad e integrada y perteneciente al sistema cultural, un individuo o comunidad enculturizados, es decir, que han desarrollado una capacidad en lo patrimonial y saben ejercerla de forma autónoma (Amaral, 2013). Resulta evidente que este proceso no ocurre de forma espontánea; es necesaria una acción educativa que, a través de un aprendizaje significativo y contextualizado, así como de un trabajo actitudinal y la incorporación de procesos basados en la participación y experimentación colectiva, posibilite estos procesos de patrimonialización.

Es en este lugar transitorio y consciente de su posición interterritorial que aparece la figura del artista mediador, que busca provocar, estimular y articular los diversos repertorios, códigos e inquietudes de los sujetos en sus relaciones entre sí y con los contextos en los que se inscriben. Desea traer al lugar del encuentro los códigos-lenguajes, deseos y visiones del mundo de los individuos, grupos sociales y contextos, creando un campo relacional en el que todos estos componentes se configuran como plataforma sobre la cual se desarrollan los dispositivos del arte contemporáneo como praxis de mediación (Amaral, 2013).

Podríamos decir que los procesos de patrimonialización desde la comunidad no buscan consensuar nuevos significados en un entorno identitario ya conformado, sino generar nuevos entornos identitarios que ayuden a la comunidad a dotar de sentido al contexto. Por tanto, el proceso de patrimonialización a nivel comunitario es la consecuencia de una maduración del proceso de patrimonialización institucional (Falcón, 2010). La comunidad, a través de un aprendizaje en base a una herencia, aprende también a generar sus propios productos, es decir, es el proceso propio de una cultura patrimonializada, sólida y segura de sus referentes, una cultura que contempla el patrimonio como hilo conductor de su propia historia pasada y futura.

Sin embargo, este proceso creativo no pretende una producción masiva 
de patrimonios, lo que a priori puede desprenderse de una ampliación del concepto, sino que pretende redefinir el concepto en la búsqueda de nuevas definiciones y discursos que tengan cabida en los nuevos entornos contemporáneos (Torregrosa y Falcón, 2013).

Así pues, definir el proceso de patrimonialización en un entorno en el que los significados y contextos tienen que volver a definirse, remite a la base del proceso autónomo de patrimonialización, es decir a la actitud patrimonializadora. No sirve contextualizar en el presente, ya que el potencial patrimonio al que nos referimos ha sido generado en el presente; es, por tanto, un producto de éste y, por definición, está contextualizado y tiene un sentido en este tiempo. El proceso de patrimonialización desde la creación supone, de esta manera, una reflexión, una mirada propia hacia el interior de la cultura, una búsqueda en la marea de productos y construcciones culturales de esos patrimonios, o finalmente, esa representatividad del entorno que se pretende perpetuar.

\section{Enfoque educativo de los}

\section{procesos de patrimonialización:}

\section{hacia una secuencia procedimental}

Una vez desarrollado el enfoque cultural de los procesos de patrimonialización, en sus tres dimensiones (institucional, cultural y comunitaria), nos aproximamos a una mirada educativa hacia esos mismos procesos de patrimonialización, que acaba resultando clave para sustentarlos. En efecto, hemos abordado una visión del patrimonio basada en la idea de vínculos entre bienes y personas, de modo que la educación es esa disciplina clave que media, actúa y programa en relación con esos vínculos.

La secuencia procedimental dirigida a la patrimonialización desde la educación.

La siguiente secuencia pretende ordenar la arquitectura didáctica en torno a la patrimonialización desde esta dimensión educativa, con el fin de estructurar y equilibrar las fuerzas que la constituyen:

- Conocimiento para la comprensión.

- Comprensión para la puesta en valor.

- Puesta en valor para la apropiación simbólica.

- Apropiación simbólica para el cuidado/conservación.

- Cuidado para el disfrute.

- Disfrute para la transmisión (Fontal, 2003, p.171-181).

Conocer para comprender: Para poder disfrutar de un bien o un valor artístico, es preciso algo tan sencillo como conocer su existencia. Trabajar el conocimiento permite obtener algunas claves para la comprensión del elemento. Para conseguir esto, la comprensión ha de centrarse, por una parte, en un nivel significativo, donde exista certeza de la existencia de unos conocimientos previos (fase anterior de la secuencia) y, a partir de ahí, constructivamente, ir aportando 
claves de la comprensión, que den sentido, que expliquen porqués y paraqués.

Comprender para respetar: El respeto es un contenido fundamentalmente actitudinal; respetamos aquello que entendemos antes que aquello otro que no tiene sentido, valor o interés. Por eso, el procedimiento anterior es fundamental en esta secuencia. Trabajar el respeto, puede hacerse desde aquellos elementos que tienen una implicación directa con los sujetos que aprenden, en una escala más cercana, como la individual o la familiar. En estos casos, las implicaciones emotivas son mayores y los dos procedimientos anteriores de la secuencia no necesariamente han de trabajarse, por lo que se conoce el elemento y se comprende, incluso se valora. Esto permite trabajar lo actitudinal sobre vínculos ya existentes.

Respetar para valorar: Para valorar un bien es preciso, además de conocerlo, comprender sus razones, sus claves y su propia lógica. Esto nos permitirá contar con argumentos suficientes para su valoración, que no son otra cosa que conocimientos previos. En este sentido, podemos afirmar que valoramos aquello que comprendemos (porque tiene sentido) y que, por tanto, respetamos. Así, la valoración es un núcleo de gran relevancia dentro de la enseñanza-aprendizaje del patrimonio. Para que exista la valoración, es preciso un proceso previo de attribution, que traduciríamos como asignación, incluso significación que, en definitiva, requiere de la comprensión (eslabón procedimental anterior) y conduce a la valoración (Dubé, 2002, p.314).

Valorar para sensibilizar: Aquello que tiene valor nos preocupa y ocupa nuestro tiempo, muchas veces también nuestros recursos. Al contrario, todo aquello a lo que no concedemos valor -lo cuál no impide que lleguemos a atribuírselo- no tiene por qué importarnos. Dicho de otro modo, somos sensibles cuando tendemos vínculos de relevancia. Valorar es por tanto un procedimiento clave en los procedimientos, que una vez conseguido, da lugar a la sensibilización. Los procedimientos anteriores -conocer, comprender, respetar- son fundamentales como antecedentes de la valoración, pero también se relacionan directamente con la sensibilización. Una vez estamos sensibilizados con determinada realidad, mostramos una disposición a cuidarla.

Cuidado, disfrute y transmisión: Dado que los elementos patrimoniales -ya sean materiales, inmateriales o espirituales- están sujetos a la acción humana y natural, son perecederos. Aquello que no se conoce, difícilmente se puede cuidar; lo mismo sucede si no se comprende, no se respeta o no se valora. De hecho, aquello que consideramos que tiene un gran valor, tendemos a protegerlo y a conservarlo. Con respecto a los valores y elementos inmateriales del patrimonio, el conocimiento, la difusión y la mediación educativas se convierten en las mejores formas de preservar, conservar y restaurar esos 
elementos culturales. El cuidado es, finalmente, una forma de intervención sobre el patrimonio, de manera que es preciso ser conscientes de este poder por parte del receptor y adoptar una postura específica con relación al modo en que queremos legar ese bien. El cuidado comprende, desde una valoración o puesta en valor (si carece de él) de lo percibido, el cuidado físico hacia la materialidad de la obra (no romperla, no agredirla...), a su inmaterialidad (no referirse a ella de forma despectiva, respetar a sus creadores...) y a su transmisión (procurar "contagiar" ese cuidado a otros sujetos y grupos).

El disfrute desencadena una serie de respuestas lógicas hacia el patrimonio. Aquello que nos produce delectación es un estímulo positivo y, como tal, deseamos que se produzca en más ocasiones. Este disfrute puede producirse a muchos niveles: emotivo, científico, emocional, experimental, relacional (relaciones humanas), físico, sensorial y cognitivo (Fontal, 2003, p.208-209), que condicionan el enfoque educativo y el aprendizaje relacionado con la delectación.

\section{De la patrimonialización a la identización}

Entendemos que es necesario patrimonializar para identizar, en tanto se precisa una propiedad simbólica del patrimonio para poder posteriormente generar una identidad colectiva, una pertenencia real. Así pues, la secuencia procedimental para la identización se genera a partir de la premisa: es nece- sario que considere el bien patrimonial como "mío" para que me defina.

El proceso de patrimonialización aparece como sustrato, como base nutritiva de un proceso de identización, que crece con el proceso de patrimonialización, es decir, precisa recorrer el itinerario marcado por los hitos dinámicos de la secuencia procedimental establecida por Fontal (2003) para poder establecer sus propios hitos y procedimientos.

Sin embargo, analizando para nuestro fin la secuencia para la patrimonialización, comprendemos que quedaría dividido por una doble intencionalidad, un primer cuerpo de procesos que tendrían como dirección y objeto aprender a patrimonializar (entendido aquí como significar y dotar de sentido) para poder alcanzar el segundo cuerpo de procedimientos que se caracterizan como la praxis cultural del proceso aprendido.

Tomando la primera parte de la secuencia de patrimonialización (más implicada en el proceso de enseñanzaaprendizaje) como sustrato de esta otra, la secuencia para la identización quedaría dibujada a través del itinerario procedimental: conocer-comprender-respetar-valorar-patrimonializaridentizar a nivel individual-compartirconsensuar-identizar a nivel colectivo (Gómez-Redondo, 2013). Cabe ahora profundizar en los procedimientos propios de la secuencia de identización:

Patrimonializar: Es necesario sentir algo como propio para que pueda formar parte de la identidad. Por lo tanto, hablamos de patrimonializar como una 
apropiación simbólica, cuya adquisición se realiza a partir de la vinculación significativa del individuo con el objeto patrimonial, es decir, a partir de la generación de significados propios y vínculos afectivos. De este proceso se infieren, además, actitudes de participación activa: saberse agente del proceso, apertura, enriquecimiento, deseo de perdurabilidad, etc.

Identizar (nivel individual): Para poder generar una identidad colectiva es necesario ser consciente y gestor de la identidad propia. Ser consciente del carácter dinámico y polimorfo de la identidad supone adquirir un papel agente en esa gestión. Identizarse significa asumir o "digerir" un patrimonio, algo que ya estaba vinculado al individuo a través de la propiedad, como propio y definitorio. Supone asumir que lo que es propio, significativamente, define. Supone un mayor conocimiento personal, una actitud positiva hacia el crecimiento personal, responsabilidad, coherencia, pertenencia, respeto, una ecología con el entorno, una actitud autogestora a nivel cognitivo y afectivo.

Compartir: Un procedimiento intermedio en los estratos de colectivización identitarios a nivel patrimonial, supone compartir los significados que previamente se han generado a nivel individual. Este proceso deviene en un hecho social significativo por sí mismo, en tanto cada individuo analiza, gestiona y filtra lo que desea compartir, otorgándole en este mismo acto un valor, una preg- nancia por el hecho de creer adecuada su comunicación. Desarrollará, por tanto, actitudes individuales como la generosidad, la pertenencia, solidaridad, etc. y actitudes sociales de escucha, aceptación, apertura, positividad, respeto, etc.

Consensuar: Complementariamente al compartir, pero establecido como un proceso propio y necesariamente posterior, aparece el ámbito del consenso. Consensuar primeramente dibuja el campo colectivo. Si compartir era el punto inicial de la apertura de lo individual hacia lo colectivo, el consenso ratifica una plena aceptación del ámbito del "nosotros". A partir de esta colectividad formada, es posible otorgar significados; consensuar viene a ser el "comprender" individual pero a un nivel colectivo. Aparecen, pues, actitudes de respeto, pertenencia, valoración de lo común, aprecio de la singularidad, escucha, igualdad, solidaridad, afectividad, etc.

Identizar (nivel colectivo): El consenso como proceso va dibujando la identidad colectiva, entendida al igual que la identidad individual como una construcción discursiva y poli-sustancial. Del consenso aparecen las señas identitarias, como abstracciones de la praxis particular, se crea así un universo referencial colectivo. Supone actitudes de pertenencia, inclusión, gestión positiva del individuo, solidaridad, igualdad, respeto, afectividad y un largo etcétera que recoge, en base a un aprendizaje significativo, las actitudes de procedimientos anteriores. 


\section{El Plan Nacional de Educación y Patrimonio y los procesos de patrimonialización}

Como consecuencia de la argumentación expuesta en los anteriores apartados, parece pertinente considerar que aquellos programas educativos que se centran en los procesos de patrimonialización e identización del patrimonio, ciertamente están situándose en lo que consideramos esencia o clave de la educación patrimonial, en tanto son capaces de ordenar secuenciadamente los vínculos que se establecen entre bienes y personas. Justamente, este es un criterio metodológico que se señala en el Plan Nacional de Educación y Patrimonio (en adelante $\mathrm{PNEyP})^{1}$, referido a la sensibilización, que:

[...] requiere atención educativa y la diferenciación de varias fases previas y posteriores a este estado en el que el Patrimonio nos importa, nos preocupa lo que le suceda y por ello nos ocupamos de él, dedicándole recursos económicos y humanos.(...) No es posible valorar aquello a lo que no se encuentra sentido. Comprender el Patrimonio significa reconocer que tiene un significado histórico, social, político, e identitario; precisamente lo que después se denominan valores patrimoniales. (...) Aquello que tiene valor, que importa en definitiva, será objeto de atención por parte de los ciudadanos, de los gestores de Patrimonio, de las administraciones y de los investigadores. Por lo tanto, es un primer paso fundamental que se reconozca el valor de un determinado bien patrimonial, pero que sea un reconocimiento propio y no impuesto, que las personas hayan experimentado procesos y situaciones que les conduzcan a ser ellos mismos quienes atribuyan valor a ese Patrimonio. A partir de aquí la tendencia humana es cuidar lo que tiene valor, velar porque no se deteriore, restaurándolo si resulta necesario, darlo a conocer a otros e implicarlos en su cuidado. Pero el ser humano también debe ser educado en el cuidado y la difusión, pues hay criterios y pautas, técnicas específicas, mecanismos especializados y medios tecnológicos que nos permiten hacerlo con eficacia y perdurabilidad (Domingo, Fontal y Ballesteros, 2013, p.15-16).

Por tanto, el PNEyP contempla la importancia de los procesos de patrimonialización, entendiendo que los bienes culturales que forman parte del patrimonio son considerados como tales en virtud del acto de patrimonialización realizado por el colectivo o sociedad que es su titular, es decir en virtud de la relación existente entre estos bienes y las personas que los dotan de valores culturales. Por eso, desde el PNEyP se

\footnotetext{
${ }^{1}$ Los Planes Nacionales se generan desde el Instituto del Patrimonio Cultural de España (IPCE), y son instrumentos de coordinación interadministrativa, que permiten establecer criterios metodológicos para definir programas y líneas de actuación en la gestión del patrimonio cultural. Uno de estos planes es el PNEyP, aprobado en 2013 y que se encuentra en periodo de implementación.
} 
considera que la educación patrimonial es doblemente relacional, pues se ocupa de las relaciones entre personas y entre éstas y los aprendizajes. De este modo, el patrimonio es el contenido de ese aprendizaje y las formas de relación se refieren a la identidad, propiedad, cuidado, disfrute, transmisión, etc. (Domingo, Fontal y Ballesteros, 2013).

Además del PNEyP, en nuestro país contamos con un instrumento centrado en la observación permanente de la educación patrimonial, denominado Observatorio de Educación Patrimonial en España. Justamente uno de los objetivos del Plan es el fomento de la investigación en educación patrimonial, buscando el seguimiento de las acciones y líneas proyectuales desarrolladas en la materia de educación patrimonial, tanto en el ámbito nacional como en el internacional. Esta línea de investigación se realiza desde el Observatorio de Educación Patrimonial en España, favoreciendo la consolidación del mismo (Domingo, Fontal y Ballesteros, 2013, p.9).

\section{La evaluación de programas de educación patrimonial desde el Observatorio de Educación Patrimonial en España (OEPE)}

Además de estar integrado en el propio Plan Nacional de Educación y Patrimonio, el OEPE es la principal transferencia derivada de dos proyectos de I+D+i nacionales financiados por el Ministerio de Economía y Competitividad $^{2}$. Desde este observatorio se ha generado una base de datos (Base OEPE) en la cual se recoge, de manera sistemática, información relativa a programas de educación patrimonial que se han llevado a cabo en España y en el ámbito internacional durante los últimos 15 años. El proceso, que se inicia con la búsqueda y localización de programas, concluye en el estudio de casos, tras pasar por diversas fases que seleccionan, progresivamente, aquellos programas que reúnen estándares de calidad evaluables, generales y específicos de su tipología educativa, conforme al siguiente esquema:

\section{Cuadro I \\ Sistema de selección y evaluación de programas OEPE}

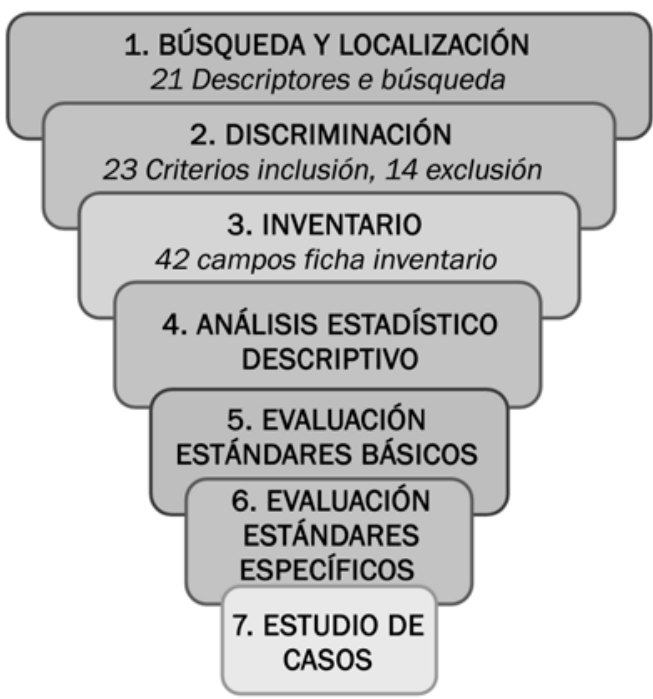

Fuente: Elaboración propia

\footnotetext{
${ }^{2}$ EDU2009-09679 (1-1-2010 a 31-12-2012) y EDU2012-37212 (1-1-2013 a 31-12-2015). Ambos proyectos, cuya IP es la Dra Fontal, se inscriben en el programa de Investigación Fundamental no Orientada.
} 
$1^{\circ}$. Búsqueda y localización de programas conforme a 21 descriptores de búsqueda definidos por el equipo de investigación y 12 expertos internacionales consultados.

$2^{\circ}$. Discriminación. Sobre la relación de programas localizados, aplicamos una serie de 23 criterios de inclusión y 14 de exclusión para su inventario en la base de datos, que definen un universo de programas introducidos.

$3^{\circ}$. Inventario. Cada programa educativo se introduce en la ficha de datos OEPE de forma exhaustiva por los investigadores, lo que nos permite la documentación sistemática de programas $^{3}$.

\section{Cuadro II}

\section{Descripción de la ficha de inventario del OEPE}

\begin{tabular}{|l|l|}
\hline APARTADO & SUBAPARTADOS \\
\hline Identificación+localización & $\begin{array}{l}\text { Título del proyecto, Entidad responsable, Comunidad autónoma, Provincia, } \\
\text { Localidad, Dirección postal, Teléfonos de contacto, Personas responsables: } \\
\text { Nombre, Apellidos, Email, Dirección Web, Investigador, Otros }\end{array}$ \\
\hline Relación con otras fichas & $\begin{array}{l}\text { En este apartado se abre un menú desplegable con los proyectos que ya están } \\
\text { recogidos en la base de datos. Se trata de relacionar el nuevo proyecto con alguno } \\
\text { de éstos en el caso de que sean complementarios o promovidos por una misma } \\
\text { institución/organización. Además pueden introducirse observaciones aclaratorias } \\
\text { sobre dicha relación. Se trata de aportar toda la información disponible en torno al } \\
\text { proyecto o programa que está siendo analizado. }\end{array}$ \\
\hline Descripción & \\
\hline &
\end{tabular}

${ }^{3}$ La ficha de inventario se organiza en 5 grandes apartados, que suman 42 campos: (1) Identificación, (2) localización, (3) relación con otras fichas, (4) descripción y datos del diseño educativo y (5) Anexo documental 


\begin{tabular}{|c|c|c|}
\hline ITEMS & Categorías & Subcategorías \\
\hline \multirow{12}{*}{$\begin{array}{l}\text { Categoría de proyecto } \\
\text { (las categorías han sido } \\
\text { definidas en función de } \\
\text { las categorías } \\
\text { introducidas por la } \\
\text { UNESCO en relación a } \\
\text { los tipos de patrimonio } \\
\text { cultural). }\end{array}$} & \multirow[t]{6}{*}{ 1. Monumentos } & $\begin{array}{l}\text { Obra arquitectónica: construcción arquitectónica con valor } \\
\text { excepcional desde el punto de vista de la historia, el arte o la } \\
\text { ciencia. }\end{array}$ \\
\hline & & $\begin{array}{l}\text { Obra escultórica: escultura con valor excepcional desde el } \\
\text { punto de vista de la historia, del arte o de la ciencia. }\end{array}$ \\
\hline & & $\begin{array}{l}\text { Obra pictórica: pintura, collage, grafiti, mural, etc. Con valor } \\
\text { excepcional desde el punto de vista de la historia, del arte o la } \\
\text { ciencia. }\end{array}$ \\
\hline & & $\begin{array}{l}\text { Obra arqueológica: elementos arqueológicos con valor } \\
\text { excepcional desde el punto de vista de la historia, del arte o la } \\
\text { ciencia. }\end{array}$ \\
\hline & & $\begin{array}{l}\text { Inscripciones en cavernas: puntura o inscripciones rupestres } \\
\text { con valor excepcional desde el punto de vista de la historia, } \\
\text { del arte o la ciencia. }\end{array}$ \\
\hline & & Grupo de elementos de importancia histórico artística. \\
\hline & \multirow[t]{2}{*}{ 2. Conjuntos } & Construcciones aisladas. \\
\hline & & Construcciones reunidas. \\
\hline & \multirow[t]{4}{*}{ 3. Lugares } & Creados por el hombre. \\
\hline & & Creados por el hombre y la naturaleza. \\
\hline & & Lugares arqueológicos. \\
\hline & & Lugares especiales. \\
\hline & 4. Patrimonio Digital & $\begin{array}{l}\text { El patrimonio digital consiste en recursos únicos que son fruto } \\
\text { del saber o la expresión de los seres humanos. Comprender } \\
\text { recursos de carácter cultural, educativo, científico o } \\
\text { administrativo e información técnica, jurídica, médica y de } \\
\text { otras clases, que se generan directamente en formato digital o } \\
\text { se convierten a éste a partir de material analógico ya existente. } \\
\text { Los productos "de origen digital" no existen en otro formato } \\
\text { que el electrónico. }\end{array}$ \\
\hline & 5. Patrimonio Inmaterial & $\begin{array}{l}\text { Tradiciones o expresiones vivas heredadas de nuestros } \\
\text { antepasados y transmitidas a nuestros descendientes, como } \\
\text { tradiciones orales, artes del espectáculo, usos sociales, } \\
\text { rituales, actos festivos, conocimientos y prácticas relativos a la } \\
\text { naturaleza y el universo, y saberes y técnicas vinculados a la } \\
\text { artesanía tradicional. }\end{array}$ \\
\hline & 6. Otros & $\begin{array}{l}\text { En esta categoría se incluyen aquellos tipos de patrimonio que } \\
\text { no se relacionan con ninguna de las categorías anteriores. }\end{array}$ \\
\hline \multirow[t]{2}{*}{$\begin{array}{l}\text { Adaptación a } \\
\text { discapacitados }\end{array}$} & $\mathrm{Si}$ & $\begin{array}{l}\text { Recursos humanos } \\
\text { Recursos técnicos } \\
\text { Recursos materiales }\end{array}$ \\
\hline & \multicolumn{2}{|l|}{ No } \\
\hline $\begin{array}{l}\text { Tipo de adaptación (si } \\
\text { existe) }\end{array}$ & \multicolumn{2}{|r|}{ n tipo de adaptación especial (de materiales, arquitectura, etc.). } \\
\hline
\end{tabular}




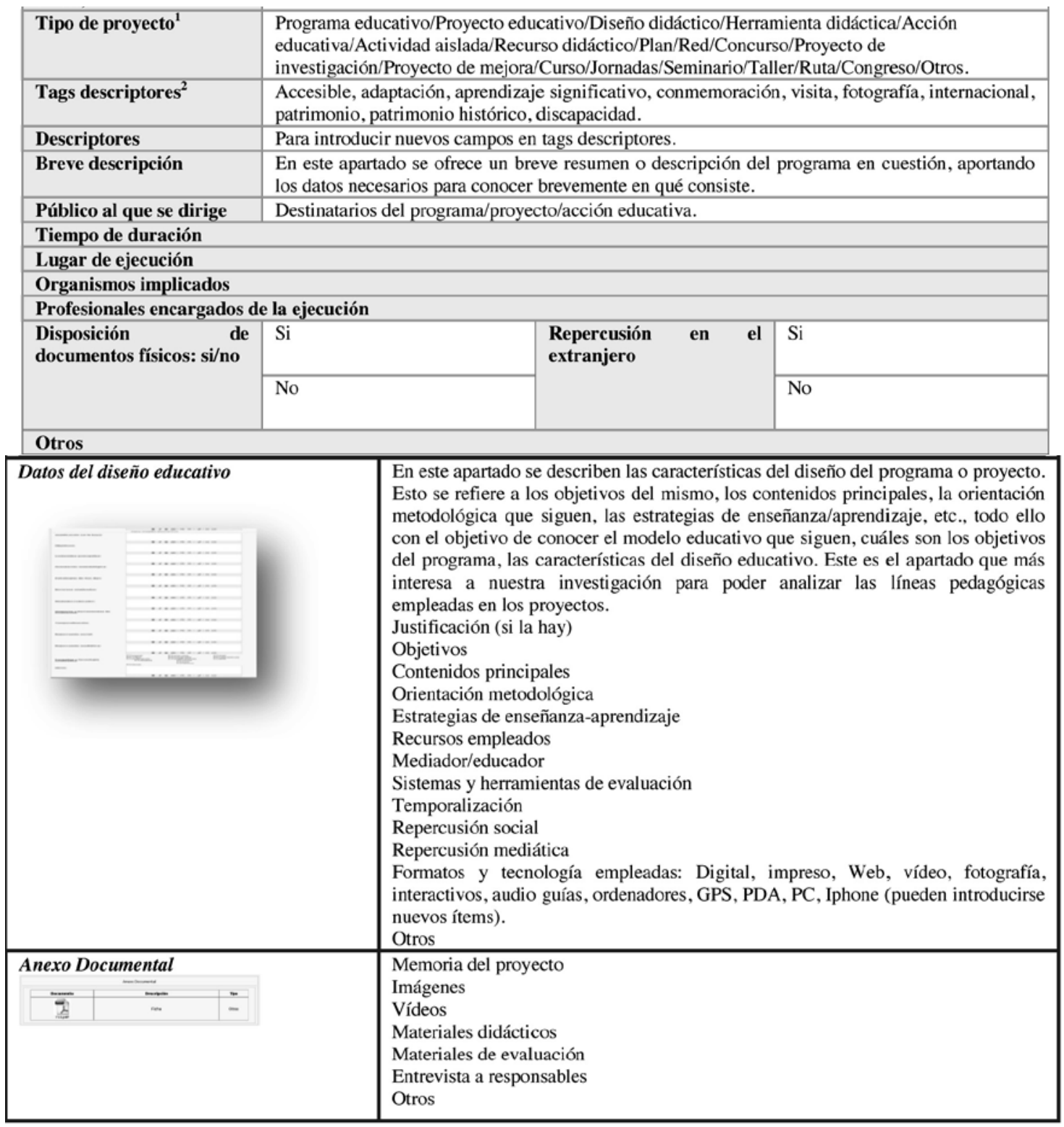

Fuente: Elaboración propia.

$4^{\circ}$. Análisis. Con las diferentes muestras de programas, realizamos análisis estadistico- descriptivos periódicos (cada 500 programas), que nos permiten obtener datos cuantitativos cen- trados en los porcentajes de frecuencia relacionados con la geolocalización, su relación con las tipologías educativas, categorías de patrimonio, destinatarios, ámbitos educativos, intencionalidad 
educativa y enfoques sobre los que se sustentan. También se realizan análisis relacionales entre los datos obtenidos en los campos de los diferentes apartados de la ficha entre sí. Además, se efectúan análisis del contenido de programas que se presentan en formato escrito y cuyo diseño educativo tiene un alto nivel de explicitación; también se analiza toda la normativa patrimonial y educativa. Estos análisis se centran en cuatro grandes categorías: concepciones (de la educación patrimonial, del patrimonio y del diseño educativo), elementos clave del diseño (finalidad, objetivos, contenidos, secuenciación y metodología), destinatarios (niveles socio-cultural, cognitivo, relacional y patrimonial) y evaluación.

$5^{\circ}$. Selección en base a estándares. El resultado de los anteriores análisis nos permite definir estándares generales y específicos para cada tipología educativa, que nos servirán para obtener una muestra de los programas que mejor los alcanzan en lo referente al diseño, la implementación, los resultados y su difusión.

$6^{\circ}$. Evaluación de programas. Posteriormente se seleccionan aquellos programas que mayor nivel de adecuación a estándares tienen, para realizar una evaluación extendida, donde se incluye una evaluación comprensiva relacionada con su tipología educativa (Stake, 2006b).

\section{Cuadro III}

\section{Descripción metodológica relacionada con la evaluación de programas}

\begin{tabular}{|c|c|c|c|c|}
\hline \multicolumn{5}{|c|}{ EVALUACIÓN DE PROGRAMAS } \\
\hline $\begin{array}{l}\text { DIMENSIÓN DEL } \\
\text { POGRAMA A } \\
\text { EVALUAR }\end{array}$ & $\begin{array}{l}\text { CRITERIO A } \\
\text { EVALUAR }\end{array}$ & MÉTODOS & $\begin{array}{l}\text { TÉCNICAS DE } \\
\text { RECOGIDA DE } \\
\text { DATOS }\end{array}$ & $\begin{array}{l}\text { TÉCNICAS DE } \\
\text { ANÁLISIS DE } \\
\text { DATOS }\end{array}$ \\
\hline \multirow[t]{2}{*}{$\begin{array}{l}\text { Orientación y Diseño } \\
\text { educativo }\end{array}$} & $\begin{array}{l}\text { Pertinencia } \\
\text { Relevancia }\end{array}$ & \multirow{2}{*}{$\begin{array}{l}\text { Análisis de } \\
\text { contenido } \\
\text { (descriptivo, } \\
\text { explicativo e } \\
\text { interpretativo) }\end{array}$} & \multirow{2}{*}{$\begin{array}{l}\text { Plantilla de registro } \\
\text { Sesiones de grupo } \\
\text { Téenica Delphy }\end{array}$} & \multirow[t]{2}{*}{$\begin{array}{l}\text { Análisis descriptivos y } \\
\text { ordinales. }\end{array}$} \\
\hline & $\begin{array}{l}\text { Suficiencia } \\
\text { Viabilidad }\end{array}$ & & & \\
\hline \multirow[t]{3}{*}{$\begin{array}{l}\text { Implementación del } \\
\text { programa }\end{array}$} & Progreso & $\begin{array}{l}\text { Seguimiento } \\
\text { temporal }\end{array}$ & Fichas de registro & Evolución cronológica \\
\hline & Participación & $\begin{array}{l}\text { Encuesta (estudio } \\
\text { de públicos) }\end{array}$ & Cuestionario & $\begin{array}{l}\text { Análisis cuantitativo y } \\
\text { de variables }\end{array}$ \\
\hline & $\begin{array}{l}\text { Eficacia } \\
\text { (consecución de } \\
\text { objetivos previstos) }\end{array}$ & Grupo de discusión & $\begin{array}{l}\text { Protocolo para Grupo } \\
\text { de Discusión }\end{array}$ & $\begin{array}{l}\text { Análisis cualitativo } \\
\text { (Programa ATLASti) }\end{array}$ \\
\hline Efectos & $\begin{array}{l}\text { Satisfacción } \\
\text { Utilidad de los } \\
\text { resultados a corto y } \\
\text { medio plazo }\end{array}$ & $\begin{array}{l}\text { Encuestas y } \\
\text { Entrevistas }\end{array}$ & $\begin{array}{l}\text { Cuestionario y } \\
\text { Guión de entrevista }\end{array}$ & $\begin{array}{l}\text { Análisis descriptivos y } \\
\text { correlacionales. } \\
\text { Análisis cualitativo. }\end{array}$ \\
\hline TRIANGULACIÓN & & $\begin{array}{l}\text { TRIANGULA } \\
\text { ANGULACIÓN }\end{array}$ & $\begin{array}{l}\text { ÓN DE MÉTODOS } \\
\text { NIVELES COMBI }\end{array}$ & os \\
\hline
\end{tabular}

Fuente: Elaboración propia. 
$7^{\circ}$ Estudio de casos. Los programas que destacan por su excelencia en la anterior evaluación, son seleccionados para realizar estudio de casos. Estos casos nos permiten, a su vez, definir nuevos criterios y parámetros para el siguiente ciclo de búsqueda y localización.

Como resumen, mostramos las muestras recogidas en cada fase entre 2010 y 2015 :

\section{Cuadro IV \\ Muestras por fases}

\begin{tabular}{|l|l|}
\hline Fase de selección & Muestra 2010-2015 \\
\hline $1^{\circ}$. Búsqueda y localización & 6.230 \\
\hline $2^{\circ}$. Inclusión y exclusión de programas & 2.340 \\
\hline $3^{\circ}$. Inventario $/ 4^{\circ}$. Análisis estadístico & 1.644 \\
\hline $5^{\circ}$. Evaluación de estándares básica & 135 \\
\hline $6^{\circ}$. Evaluación de estándares extendida & 50 \\
\hline 7. Estudio de casos & 6 \\
\hline
\end{tabular}

Fuente: Elaboración propia.

Así pues llegamos a final de una secuencia que ha permitido que se expliciten los estándares generales y específicos para las diferentes tipologías de programas en educación patrimonial y que giran en torno a la solidez teórico-metodológica, la consistencia y coherencia teórico-empírica, la continuidad y estabilidad temporal, la interdisciplinariedad del patrimonio y de las didácticas que se ocupan de trabajarlo educativamente, la internacionalización de los conceptos, de los diseños y de las implementaciones, el aprovechamiento del potencial de las TIC, la coordinación entre agentes educativos, los enfoques procesuales basados en los vínculos entre bienes y personas, la diversificación y singularización de los educandos y públicos, la ordenación desde los micro-patrimonios hasta los macro-patrimonios y, por último, la incorporación de la evaluación en la programación e implementación en educación patrimonial.

\section{Análisis de tres programas referentes en procesos de patrimonialización e identización}

Una vez presentada la metodología de la investigación y su justificación en el marco del Plan Nacional de Educación y Patrimonio y del propio Observatorio de Educación Patrimonial en España, proponemos el análisis de tres programas seleccionados como casos, teniendo como centro fundamental la evaluación de la orientación y el diseño educativo desde el enfoque patrimonial. Los instrumentos de recogida de datos empleados para esta evaluación concreta son la ficha de inventario y las

\footnotetext{
${ }^{4}$ Se han definido, validado y dado a conocer en la comunidad científica los estándares generales de las 18 tipologías educativas de programas, así como los estándares específicos para cada tipología. Los estándares básicos han sido definidos partiendo de los 3 primeros análisis estadístico-descriptivos $(\mathrm{n}=350$, 644 y 1120), e incluyendo los criterios derivados del PNEyP (Plan Nacional de Educación y Patrimonio), y que se refieren a la calidad de la información sobre el programa y el grado de concreción del diseño.
} 
tablas de estándares "básica" y "extendida" para proyecto educativo y acción educativa. Ofrecemos una selección de dicha evaluación con la intención de presentar y comentar aquellos aspectos clave de esos programas, que los sitúan como referentes en los procesos de identización y patrimonialización.

\section{Proyecto educativo: "Baética"}

El proyecto educativo "Baética" fue llevado a cabo en el entorno educativo formal, en la comunidad de Andalucía. Este proyecto presenta tres vertientes de investigación: por un lado la histórica, a través de la profundización en el conocimiento de la zona en tiempos de ocupación romana; otra vertiente de desarrollo la encuentra en las tecnologías, empelando la red de conocimiento de Averroes y la creación de hipótesis virtuales de yacimientos, y finalmente una tercera vertiente en lo educativo, a través de la propuesta de innovación educativa que involucra a toda la comunidad escolar a través de las comunidades de aprendizaje. Este ejemplo ha sido seleccionado para la ejemplificación de los procesos de patrimonialización a nivel institucional.

En este caso existe un estudio previo del contexto en el que se inscribe, aunque analizando el nivel de exhaustividad y rigor del estudio vemos que presenta un nivel medio de revisión bibliográfica y documentación específica relacionada con el entorno patrimonial, pero no presenta una detección previa de vínculos entre contexto y ele- mento. No hay un conocimiento directo del elemento patrimonial en su contexto, ni se aprecia existencia previa de vínculos patrimoniales a nivel individual ni colectivo.

Baética presenta fines patrimoniales, pretende dar a conocer bienes culturales, profundizar en el conocimiento de contenidos relacionados con el elemento sobre el que centra su interés, aunque sin generar nuevos contenidos y significados en torno al elemento. $\mathrm{Y}$ entre sus finalidades se encuentra el generar productos relacionados con el elemento, en este caso una hipótesis de virtualización de yacimientos. Respecto a los vínculos entre individuo $\boldsymbol{y}$ patrimonio, pretende generar vínculos patrimoniales a nivel individual, pero no colectivo. Además, no existe una pretensión de comparación de datos al comienzo y en la finalización del proyecto. Respecto al estudio de recursos necesarios para la implementación, se observa que sí existe un estudio previo, en el que aparece un nivel medio de formación específica de los formadores, aunque no existe un contacto directo con los bienes patrimoniales; sin embargo, el conocimiento de éstos obtenido desde fuentes indirectas es elevado.

En la documentación analizada sobre el proyecto no se formulan objetivos relacionados con el ámbito patrimonial, y éstos no son clasificados en conceptuales, procedimentales y actitudinales. Aunque de un análisis y clasificación propios se desprende que tienen mayor presencia los objetivos conceptuales y procedimentales por encima de los acti- 


\section{Cuadro V}

\section{Instrumento para el análisis sistemático del proyecto educativo: "Baética"}

\begin{tabular}{|c|c|c|c|c|c|c|c|c|}
\hline \multicolumn{9}{|c|}{ REGISTRO GENERAL } \\
\hline Título & \multicolumn{8}{|l|}{ PROYECTO BAETICA } \\
\hline $\begin{array}{l}\text { Tipología de } \\
\text { Proyecto }\end{array}$ & PROYECTO EDUCATIVO & \multicolumn{3}{|c|}{ Tags Descriptores } & \multicolumn{4}{|c|}{$\begin{array}{l}\text { APRENDIZAJE } \\
\text { SIGNIFICATIVO/INVESTIGACIÓN/NUEVAS } \\
\text { TECNOLOGÍAS/PATRIMONIO HISTÓRICO }\end{array}$} \\
\hline $\begin{array}{l}\text { Breve } \\
\text { Descripción }\end{array}$ & \multicolumn{8}{|c|}{$\begin{array}{l}\text { DISEÑO EDUCATIVO EN EL ÁMBITO FORMAL, PROPUESTO DESDE LA ADMINISTRACIÓN PARA LA ENSEÑANZA/APRENDIZAJE } \\
\text { DE CONTENIDOS PATRIMONIALES Y PARA LA DIGITALIZACIÓN DEL PATRIMONIO DE ANDALUCÍA. }\end{array}$} \\
\hline \multicolumn{9}{|c|}{ DISEÑO DEL PROGRAMA EDUCATIVO } \\
\hline \multicolumn{2}{|c|}{ Se formulan objetivos en el diseño de forma explícita } & Si:X & \multicolumn{3}{|l|}{ No: } & & & \\
\hline \multicolumn{2}{|c|}{$\begin{array}{l}\text { Los objetivos se formulan en base a la finalidad del } \\
\text { programa }\end{array}$} & Si: $\mathrm{X}$ & No: & \multicolumn{3}{|c|}{ Diferencia objetivos generales de específicos } & Si:X & No: \\
\hline \multicolumn{2}{|c|}{$\begin{array}{l}\text { Diferencia objetivos conceptuales, procedimentales y } \\
\text { actitudinales }\end{array}$} & Si: & No:X & \multicolumn{3}{|c|}{ Se formulan como competencias a alcanzar } & Si: & No: $X$ \\
\hline \multicolumn{2}{|c|}{ Los objetivos presentan interrelación y dependencia } & Si:X & No: & \multicolumn{3}{|c|}{$\begin{array}{l}\text { Aparecen objetivos para el proceso y objetivos } \\
\text { finales }\end{array}$} & Si: & No: $X$ \\
\hline \multicolumn{5}{|c|}{ Objetivos formulados } & Alto & Medio & Bajo & \\
\hline & \multicolumn{4}{|l|}{ Nivel de lenguaje específico empleado } & $\mathrm{x}$ & & & \\
\hline & \multicolumn{4}{|c|}{ Concreción y evaluabilidad de los objetivos planteados } & & & $\mathrm{x}$ & \\
\hline \multicolumn{2}{|c|}{ Se formulan contenidos en el diseño de forma explícita } & Si: $X$ & No: & & & & & \\
\hline \multicolumn{2}{|c|}{ Los contenidos se relacionan con los objetivos a alcanzar } & Si: $\mathrm{X}$ & No: & \multicolumn{3}{|c|}{ Aparecen distintos niveles de especificidad } & Si: & No:X \\
\hline Contenidos $\mathrm{fc}$ & ulados & & & & Alto & Medio & Bajo & \\
\hline & Nivel del lenguaje específico empleado & & & & $\mathrm{x}$ & & & \\
\hline & Concreción de los contenidos planteados & & & & $\mathrm{x}$ & & & \\
\hline Se formula ur & ropuesta metodológica & Si:X & No: & Apare & formul & mente & Si:X & No: \\
\hline La metodolog & mpleada potencia la participación & Si:X & No: & Poten & a el apre & ficativo & Si:X & No: \\
\hline Potencia el d & abrimiento & Si:X & No: & Prese & a adapt & scapacidades & Si: & No:X \\
\hline Aparece secu & iada en relación a objetivos y contenidos & Si:X & No: & Emple & dinámic & reativas & Si:X & No: \\
\hline Se formulan & ategias de enseñanza-aprendizaje & Si:X & No: & Apare & n forme & tamente & Si:X & No: \\
\hline Se plantean $\mathrm{e}$ & lación a objetivos y contenidos & Si:X & No: & Apare & n secue & & Si:X & No: \\
\hline Se plantean $\mathrm{e}$ & orno a un aprendizaje significativo & Si:X & No: & Son $\mathrm{p}$ & teadas & cipación & Si:X & No: \\
\hline Presentan ad & aciones para discapacidades & Si: & No:X & & & & & \\
\hline Se presentan & recursos empleados & Si:X & No: & Apare & espec & $s$ recursos & Si: & No:X \\
\hline $\begin{array}{l}\text { Los recursos } \\
\text { programa }\end{array}$ & an generado específicamente para este & Si:X & No: & Atien & $\mathrm{n}$ a las $\mathrm{e}$ & ss del público & Si:X & No: \\
\hline Se emplean $\mathrm{e}$ & lación a objetivos y estrategias & Si:X & No: & Son in & ractivos & & Si:X & No: \\
\hline $\begin{array}{l}\text { Son instrume } \\
\text { educativa par }\end{array}$ & $\begin{array}{l}\text { dentro del programa y necesitan de la acción } \\
\text { brar sentido }\end{array}$ & Si:X & No: & Prete & en apre & & Si: & No:X \\
\hline El programa & enta una temporalización específica & Si:X & No: & La ter & oralizac & detallada & Si:X & No: \\
\hline Se temporaliz & n relación a diversos criterios & Si: & No:X & & & & & \\
\hline El programa & enta un sistema de evaluación & Si:X & No: & $\mathrm{Se}$ oc & a tanto & omo de resultado & Si: & No:X \\
\hline Evalúa el pro & na propiamente & Si:X & No: & Evalú & esultad & ticipantes & Si:X & No: \\
\hline $\begin{array}{l}\text { Se plantea en } \\
\text { objetivos/con }\end{array}$ & $\begin{array}{l}\text { e a la consecución de } \\
\text { tencias }\end{array}$ & Si: & No: $\mathrm{X}$ & Espec & ca criter & ción & Si: & No: $\mathrm{X}$ \\
\hline Es un tipo de & uación cualitativa para el cambio & Si: & No:X & Espec & ca herra & valuación & Si: & No: $\mathrm{X}$ \\
\hline Las herramie & permiten evaluar el objeto de evaluación & Si: & No: $X$ & & & & & \\
\hline
\end{tabular}

Fuente: Elaboración propia.

tudinales. Los objetivos no se presentan en base a la relación individuo/patrimonio, ni en base a la relación del patri- monio como mediador entre individuos. Estos, a su vez, ponen el énfasis en la asimilación de conceptos relacionados 
con el elemento patrimonial, y no aparecen objetivos referidos a la formulación de nuevos significados relacionados con el bien, aunque sí incorporan aspectos relacionados con la innovación educativa. Además, se observa que el lenguaje específico empleado para describir los objetivos responde a un nivel medio, y estos carecen de concreción y evaluabilidad.

Por su parte, los contenidos formulados en la documentación, al igual que los objetivos, no son clasificados en conceptuales, procedimentales y actitudinales, y presenta un predominio de contenidos conceptuales y procedimentales por encima de actitudinales. En éstos no se formulan nuevas concepciones sobre patrimonio como son el patrimonio del presente o el patrimonio como vínculo. Los campos semánticos más empelados en la redacción de los contenidos son aquellos relacionados con conocer y comprender, en menor grado aquellos relacionados con cuidar, transmitir y disfrutar y, por último, no aparecen términos relacionados con respetar y valorar.

La metodología empleada potencia la participación y el descubrimiento a través de dinámicas activas y creativas. Emplean, además, el método de las comunidades de aprendizaje, aunque no aparece la secuencia de patrimonialización formulada anteriormente. Las estrategias de enseñanza-aprendizaje no siguen la secuencia establecida aunque son originales y generadas específicamente para el diseño. Las estrategias inciden de mayor manera en los obje- tivos y contenidos predominantes, es decir, inciden sobre los conceptos y procedimientos, y no están relacionadas directamente con procesos de patrimonialización. Finalmente, las estrategias trabajan contenidos relacionados con el elemento patrimonial, pero no trabajan la propia relación con el elemento ni los vínculos entre individuos a través del elemento patrimonial.

Este proyecto concuerda con las nociones principales aportadas en la sustentación teórica, en tanto en cuanto, la base de significación del objeto patrimonial es la historia, y los individuos legitiman estos significados a través del empleo de recursos "de hoy" para simular el "ayer" y, por tanto, aportan ese hilo de continuidad entre pasado, presente y futuro.

Acción educativa: "Construirse a través de la Obra de Esteban Vicente”

El diseño "Construirse a través de la Obra de Esteban Vicente" llevado a cabo en el Museo de Arte Contemporáneo Esteban Vicente, ha sido seleccionado para este artículo como ejemplo de los procesos de patrimonialización a nivel colectivo. La finalidad de este taller es construir una identidad colectiva del grupo participante, por medio de la creación de señas identitarias comunes.

Desde los resultados aportados por la implementación de la evaluación basada en estándares, se desprenden ciertos datos que dan cuenta del cumplimiento de la finalidad y de la cerca- 


\section{Cuadro VI}

\section{Instrumento para el análisis sistemático de la acción educativa: "Construirse a través de la Obra de Esteban Vicente"}

\begin{tabular}{|c|c|c|c|c|c|c|c|c|}
\hline \multicolumn{9}{|c|}{ REGISTRO GENERAL } \\
\hline Título & \multicolumn{8}{|c|}{ "CONOCERSE A TRAVÉS DE LA OBRA DE ESTEBAN VICENTE" } \\
\hline $\begin{array}{l}\text { Tipología de } \\
\text { Proyecto }\end{array}$ & DISEÑO DIDÁCTICO & \multicolumn{3}{|c|}{ Tags Descriptores } & \multicolumn{4}{|c|}{$\begin{array}{l}\text { APRENDIZAJE } \\
\text { SIGNIFICATIVO/INVESTIGACIÓN/NUEVAS } \\
\text { TECNOLOGÍAS/PATRIMONIO ARTÍSTICO }\end{array}$} \\
\hline $\begin{array}{l}\text { Breve } \\
\text { Descripción }\end{array}$ & \multicolumn{8}{|c|}{$\begin{array}{l}\text { DISEÑO EDUCATIVO EN EL ÁMBITO NO FORMAL, PRENTENDE GENERAR IDENTIDADES COLECTIVAS EN TORNO AL ARTE } \\
\text { CONTEMPORÁNEO. }\end{array}$} \\
\hline \multicolumn{9}{|c|}{ DISEÑO DEL PROGRAMA EDUCATIVO } \\
\hline \multicolumn{2}{|c|}{ Se formulan objetivos en el diseño de forma explícita } & \multicolumn{2}{|l|}{ Si:X } & & & & & \\
\hline \multicolumn{2}{|c|}{$\begin{array}{l}\text { Los objetivos se formulan en base a la finalidad del } \\
\text { programa }\end{array}$} & Si:X & No: & \multicolumn{3}{|c|}{ Diferencia objetivos generales de específicos } & Si:X & No: \\
\hline \multicolumn{2}{|c|}{$\begin{array}{l}\text { Diferencia objetivos conceptuales, procedimentales y } \\
\text { actitudinales }\end{array}$} & Si: & No:X & \multicolumn{3}{|c|}{ Se formulan como competencias a alcanzar } & Si: & No: $X$ \\
\hline \multicolumn{2}{|c|}{ Los objetivos presentan interrelación y dependencia } & Si:X & No: & \multicolumn{3}{|c|}{$\begin{array}{l}\text { Aparecen objetivos para el proceso y objetivos } \\
\text { finales }\end{array}$} & Si:X & No: \\
\hline \multicolumn{5}{|c|}{ Objetivos formulados } & Alto & Medio & \multicolumn{2}{|l|}{ Bajo } \\
\hline & \multicolumn{4}{|l|}{ Nivel de lenguaje específico empleado } & $\mathrm{x}$ & & & \\
\hline & \multicolumn{4}{|c|}{ Concreción y evaluabilidad de los objetivos planteados } & $\mathrm{x}$ & & & \\
\hline \multicolumn{2}{|c|}{ Se formulan contenidos en el diseño de forma explícita } & Si: $X$ & No: & & & & & \\
\hline \multicolumn{2}{|c|}{ Los contenidos se relacionan con los objetivos a alcanzar } & Si: $X$ & No: & \multicolumn{3}{|c|}{ Aparecen distintos niveles de especificidad } & Si:X & No: \\
\hline \multicolumn{5}{|c|}{ Contenidos formulados } & Alto & Medio & \multicolumn{2}{|l|}{ Bajo } \\
\hline & \multicolumn{4}{|l|}{ Nivel del lenguaje específico empleado } & $\mathrm{x}$ & & & \\
\hline & Concreción de los contenidos planteados & & & & $\mathrm{x}$ & & & \\
\hline Se formula u & ropuesta metodológica & Si:X & No: & Apare & formula & nente & Si:X & No: \\
\hline La metodolo & mpleada potencia la participación & Si:X & No: & Poten & el apre & icativo & Si:X & No: \\
\hline Potencia el d & brimiento & Si:X & No: & Preser & adapta & capacidades & Si: & No:X \\
\hline Aparece secu & iada en relación a objetivos y contenidos & Si:X & No: & Emple & dinámic & reativas & Si:X & No: \\
\hline Se formulan & ategias de enseñanza-aprendizaje & Si:X & No: & Apare & $\mathrm{n}$ formu & amente & Si:X & No: \\
\hline Se plantean & lación a objetivos y contenidos & Si:X & No: & Apare & n secue & & Si:X & No: \\
\hline Se plantean & rno a un aprendizaje significativo & Si:X & No: & Son pl & teadas & ipación & Si:X & No: \\
\hline Presentan ad & aciones para discapacidades & Si: & No:X & & & & & \\
\hline Se presentan & recursos empleados & Si:X & No: & Apare & n especi & recursos & Si:X & No: \\
\hline $\begin{array}{l}\text { Los recursos } \\
\text { programa }\end{array}$ & an generado específicamente para este & Si:X & No: & Atienc & a las e & s del público & Si:X & No: \\
\hline Se emplean & lación a objetivos y estrategias & Si:X & No: & Son in & ractivos & & Si:X & No: \\
\hline $\begin{array}{l}\text { Son instrume } \\
\text { educativa pa }\end{array}$ & $\begin{array}{l}\text { dentro del programa y necesitan de la acción } \\
\text { brar sentido }\end{array}$ & Si:X & No: & Preter & en aprer & & Si: & No:X \\
\hline El programa & enta una temporalización específica & Si:X & No: & La ten & oralizaci & letallada & Si:X & No: \\
\hline Se temporali & n relación a diversos criterios & Si:X & No: & & & & & \\
\hline El programa & enta un sistema de evaluación & Si: & No:X & Se ocl & tanto & mo de resultado & Si: & $\overline{N o: X}$ \\
\hline Evalúa el pro & na propiamente & Si: & No:X & Evalúa & esultado & icipantes & Si: & No:X \\
\hline $\begin{array}{l}\text { Se plantea er } \\
\text { objetivos/co }\end{array}$ & $\begin{array}{l}\text { se a la consecución de } \\
\text { tencias }\end{array}$ & Si: & No:X & Especi & a criteri & ción & Si: & No:X \\
\hline Es un tipo de & luación cualitativa para el cambio & Si: & No:X & Especi & a herra & valuación & Si: & No:X \\
\hline Las herramie & permiten evaluar el objeto de evaluación & Si: & No:X & & & & & \\
\hline
\end{tabular}

Fuente: Elaboración propia.

nía del diseño al planteamiento teórico desarrollado anteriormente. Así pues, siguiendo el orden de la plantilla diseñada en la acción educativa, sí se efec- 
túa un estudio previo de las necesidades del contexto en el que se inscribe. Está respaldada por una exhaustiva revisión bibliográfica -ítem en el que obtiene máxima puntuación- . Además se ha detectado que no existen vínculos previos entre los participantes y el elemento patrimonial con el que trabajan, ni a nivel individual ni colectivo. Evaluando la relación de la finalidad del diseño con el patrimonio, obtenemos que sí existen unos objetivos y metodología orientados hacia fines patrimoniales, y que éstos, en mayor medida, pretenden dar a conocer los elementos patrimoniales, generar nuevos contenidos en torno al elemento y generar vínculos patrimoniales a nivel individual y colectivo. En menor medida se encuentra entre sus objetivos la generación de productos relacionados y finalmente, no está entre sus objetivos la comparación de datos entre el punto de partida y el final del taller.

En relación con los recursos humanos y materiales que sí quedan reflejados en el diseño, se obtiene un alto nivel de especialización de los educadores/mediadores, además de un acceso directo al elemento patrimonial, con un menor acceso al elemento a través de medios indirectos.

Ahondando en el diseño educativo del taller, aparecen objetivos específicos relacionados con el ámbito patrimonial con mayor presencia de objetivos procedimentales y actitudinales, por encima de los conceptuales. Además, se presentan en base a la relación del individuo con el patrimonio, y a la rela- ción del patrimonio como mediador entre los individuos. Entre los objetivos señalados también aparece como relevante el énfasis en la resignificación de conceptos relacionados con el elemento patrimonial y la relación del diseño con la innovación educativa. Estos objetivos contienen, en alto grado, lenguaje específico de la disciplina y concreción y evaluabilidad de los mismos. En relación con los contenidos que aparecen reflejados en el diseño, se presentan diferenciados en conceptuales, procedimentales y actitudinales, con una mayor presencia de los últimos. Además, estos contenidos aluden a nuevos planteamientos del patrimonio como son el patrimonio de hoy y el patrimonio como vínculo. Finalmente se formulan en base a campos semánticos relacionados con la secuencia de patrimonialización señalada anteriormente: conocer, comprender, respetar, valorar, cuidar, disfrutar y transmitir.

La metodología de trabajo, potencia la participación, el descubrimiento y las comunidades de aprendizaje/interpretación y emplea dinámicas activas y participativas, así como la secuencia procedimental anteriormente señalada. Respecto a las estrategias de enseñanzaaprendizaje, son creadas específicamente para este diseño educativo y siguen la secuencia procedimental. Las estrategias muestran coherencia con los objetivos y contenidos del diseño, haciendo mayor incidencia en los objetivos y contenidos procedimentales y actitudinales. Finalmente, a través de éstas, se trabajan tanto contenidos propios del elemen- 
to patrimonial, como la relación del individuo con el elemento y de los individuos entre sí a través del patrimonio.

\section{Proyecto educativo "Invisible Maps"}

El proyecto educativo "Invisible Maps" se ha llevado a cabo en torno a la ciudad de Barcelona, planteando a través de códigos $\mathrm{QR}$, hitos de un mapa de patrimonio invisible de la ciudad. Esos códigos vinculan espacios físicos de la ciudad de Barcelona con micronarrativas individuales, que se pueden visualizar en la web generada al efecto. Este proyecto sirve aquí como ejemplo de procesos de patrimonialización vinculados a la creación colectiva de nuevos patrimonios.

Analizando los datos obtenidos de la evaluación generada para esta investigación obtenemos que sí aparece un estudio del contexto en el que se inscribe, pero en la documentación estudiada no se ofrece una revisión bibliográfica. Si se desprende una detección de vínculos previos entre el contexto y el elemento patrimonial que permite, además, un conocimiento directo del elemento en su contexto y se implementa con la existencia de vínculos patrimoniales previos, a nivel individual.

El proyecto plantea sus objetivos y metodología desde una finalidad patrimonial, por ello, pretende dar a conocer elementos patrimoniales, sin profundizar en el conocimiento de contenidos vinculados al elemento, sino que persigue generar nuevos contenidos además de productos relacionados con el patrimonio. Profundizando en los vínculos interpersonales, se desprende del estudio que pretende generar vínculos colectivos con el bien patrimonial, teniendo menor presencia los vínculos patrimoniales a nivel individual. Este diseño no pretende hacer comparativas ni recogidas de datos al inicio del proyecto, ni al final del mismo.

Profundizando en el diseño del proyecto observamos que sí aparecen formulados objetivos relacionados con el ámbito patrimonial, aunque no se clasifican en conceptuales, procedimentales y actitudinales. En este diseño tienen mayor presencia los objetivos actitudinales frente a los conceptuales y procedimentales. Los objetivos no se presentan en base a la relación individuo y patrimonio, sino que se centran en el vínculo entre individuos por medio del patrimonio. Se incorporan aspectos relacionados con la innovación educativa. Los objetivos, además, ponen énfasis en la resignificación de conceptos relacionados con el bien patrimonial, poniendo menor énfasis en la asimilación de los conceptos previos ligados al elemento. Finalmente, tanto el nivel de lenguaje específico empleado como la concreción y evaluabilidad de los objetivos responden a un nivel medio en la evaluación.

Respecto a los contenidos formulados en el diseño, de nuevo observamos que no se distinguen contenidos actitudinales, procedimentales, ni conceptuales, pero atendiendo a una clasificación propia podemos decir que tienen mayor presencia los contenidos de tipo procedimental por encima de los contenidos 
Cuadro VII

\section{Instrumento para el análisis sistemático del proyecto educativo: "Invisible Maps"}

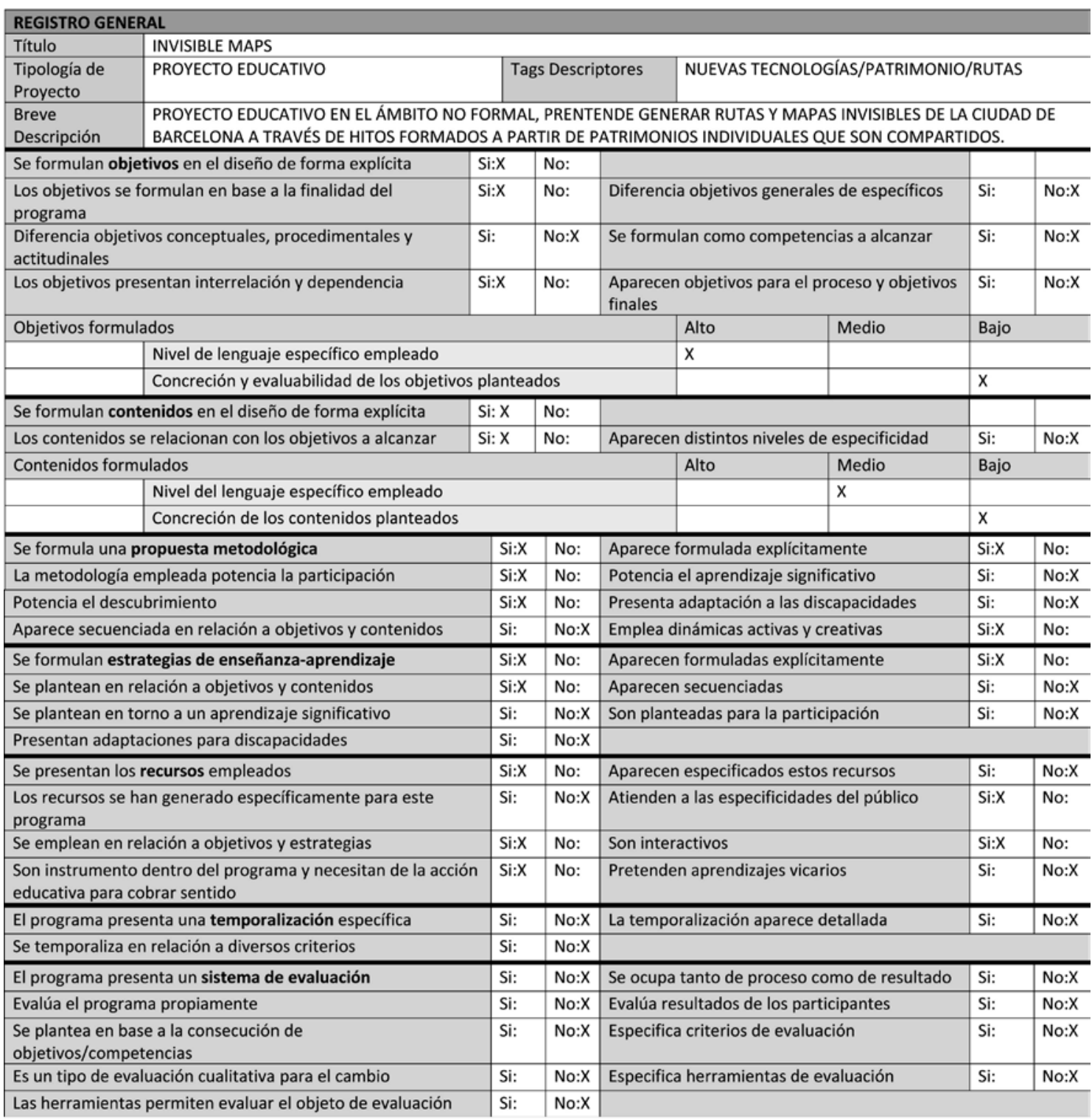

Fuente: Elaboración propia.

conceptuales y actitudinales. En este caso, sí queda patente entre los contenidos formulados el replanteamiento del concepto de patrimonio, en torno a la noción de patrimonio de hoy y de patrimonio como vínculo entre sujeto y 
objeto. Analizando los campos semánticos empleados en la formulación de los contenidos, aparecen con poca frecuencia términos relacionados con conocer y comprender, con una frecuencia intermedia, términos relacionados con respetar y valorar, y finalmente con una alta frecuencia aparecen términos relacionados con cuidar, disfrutar y transmitir.

La metodología empleada en este diseño potencia la participación a través de dinámicas activas y creativas, favoreciendo el descubrimiento. Este diseño no emplea, de manera explícita, la secuencia de patrimonialización establecida anteriormente ni las comunidades de aprendizaje como método. Respecto a las estrategias de enseñanza-aprendizaje que se formulan en este proyecto, se observa que no siguen la secuencia metodológica establecida anteriormente, aunque están relacionadas directamente con procesos de patrimonialización, por medio estrategias generadas específicamente para el proyecto. Éstas indicen, además, en mayor medida en objetivos y contenidos procedimentales, por delante de los actitudinales y conceptuales. Finalmente se desprende de la evaluación que a través de estas estrategias se trabaja la relación con el elemento patrimonial, incidiendo en menor medida en contenidos relacionados con el bien y situando su mayor interés en trabajar los vínculos entre individuos en lo patrimonial.

El proyecto "Invisible Maps" sirve aquí como ejemplo de los procesos de creación de nuevos patrimonios desde la comunidad actual y refleja procesos de colectivización como compartir y consensuar, es decir algunos de los detallados en la secuencia descrita. A través de estos procedimientos se proponen nuevos patrimonios, haciendo hincapié en el vínculo entre individuo y patrimonio a través de las narrativas individuales, que además son compartidas en la web.

\section{Conclusiones: inercias y agencias culturales}

Como ya enunciáramos al comienzo de este artículo, los nuevos paradigmas introducidos en torno al concepto de patrimonio llevan asociados nuevos enfoques en la educación patrimonial, entendida como una disciplina clave en la gestión del patrimonio (Fontal y Juanola, 2015). Esto queda reflejado en las propuestas educativas analizadas y catalogadas en el seno de la investigación del OEPE. Tras este análisis, es posible observar varias inercias educativas que, a su vez, requieren de la implicación de diversas agencias culturales:

Inercia transmisiva: ligada al concepto de patrimonio como objeto con valor propio, y en cuanto a tal, las inercias educativas van encaminadas a la transmisión/adquisición de contenidos relacionados con los significados del bien patrimonial, previamente asignados y ratificados por la sociedad.

Inercia vinculante: ligada al concepto de patrimonio como vínculo entre sujeto y objeto (Fontal, 2008) (Calaf, 2009) (Marín, 2013), de forma que las inercias educativas van encaminadas a la crea- 
ción de nuevos lazos y vínculos de significación conceptual y afectiva entre el individuo y el objeto, elemento o bien patrimonial, donde la ratificación social de significados no tiene tanto peso.

Inercia relacional: que nace a la luz de las últimas investigaciones (Falcón, 2010; Fontal, 2013; Gómez-Redondo, 2013), donde el patrimonio se configura como mediador y contexto de los vínculos entre personas. En este caso, las inercias educativas centran el protagonismo en la comunidad, la identidad y la pertenencia como contextos sociales que dotan de sentido al patrimonio y que, a su vez, éste permite generar, en estas inercias, por tanto resulta prioritario el proceso de patrimonialización frente al concepto de patrimonio como objeto.

Así pues, las inercias transmisivas suelen ser empleadas a nivel institucional e ir determinadas por el papel sancionador y ratificador de la institución y, por tanto, los diseños educativos inciden en la transmisión/adquisición de conocimientos conceptuales generalmente, que han sido previamente determinados por la institución, y que, precisamente, a través de la acción educativa y la difusión son ratificados y sancionados.

Las inercias vinculantes -que se orientan a la creación de vínculos entre sujeto y objeto-, suelen estar promovidas por entidades educativas del ámbito no formal, mucho menos ligadas a la institución y que pretenden su acción educativa para el afianzamiento de lazos de los individuos con el objeto patrimonial a fin de generar un públi- co más sensible que demande su papel agente en la construcción e ideación del entorno patrimonial.

Finalmente, las inercias relacionales utilizadas a nivel comunitario, suelen buscar dinamicidad social, y por tanto traban los procesos relacionados con la creación de vínculos entre individuos a través del patrimonio. Este tipo de instituciones se concretan en entidades museísticas con una museología social y programas sociales de entidades culturales, todo ello en un entorno educativo no formal e informal.

Esta investigación permite establecer ciertos modelos de educación según la agencia que los elabora, observándose, por tanto, distintos procesos que llevan finalmente a la patrimonialización. Así pues, las inercias y agencias culturales definidas aquí, forman un sustrato $o$ andamio que, en futuras investigaciones, pueda posibilitar el establecimiento de diferentes modelos o estructuras de diseños educativos aplicables dependiendo del tipo de proceso que se quiera seguir, y del tipo de patrimonialización que se desee obtener.

\section{Referencias bibliográficas}

AGUIRRE, I. (2008). Nuevas ideas de arte y cultura para nuevas perspectivas en la difusión del patrimonio. En V.V.A.A. El acceso al patrimonio cultural. Retos y Debates. (67-118). Pamplona: Universidad Pública de Navarra.

AMARAL, L. (2013). Patrimonios migrantes: geopolítica e identidades 
en tránsito. En R. HUERTA Y R. DE LA CALLE (coords.), Patrimonios migrantes (95-106). Valencia. UV.

BALLART, J. (1997). El patrimonio histórico y arqueológico: valor y uso, Barcelona: Ariel.

BERGER, P. y LUCKMANN, T. (2001). La construcción social de la realidad, Buenos Aires: Amorrortu.

CALAF, R. (2009). Didáctica del patrimonio. Epistemología, metodología y estudio de casos. Gijón: Trea.

CALBÓ, M; JUANOLA, R. y VALLÉS, J. (2011). Visiones Interdisciplinarias en educación del patrimonio. Girona: Documenta Universitària.

CUENCA, J. M. (2002). El patrimonio en la didáctica de las ciencias sociales: análisis de concepciones, dificultades y obstáculos para su integración en la enseñanza obligatoria. Tesis doctoral. Universidad de Huelva.

CUENCA, J. M. (2003). Análisis de concepciones sobre la enseñanza del patrimonio en la educación obligatoria. Enseñanza de las ciencias sociales: revista de investigación, 2, 37-46.

CUENCA, J. M. y ESTEPA, J. (2013). La educación patrimonial: líneas de investigación y nuevas perspectivas. En ESTEPA, J. (coord.), La educación patrimonial en la escuela y el museo: investigación y experiencias (343-355). Hueva: UH.

DOMINGO, M; FONTAL, O. y BALLESTEROS, P. (Coords.) (2013). Plan Nacional de Educación y Patrimonio. Madrid: Ministerio de Educa- ción, Cultura y Deporte /Secretaría de Estado de Cultura.

DUBÉ, P. (2002). Patrimonie et récit: quelques questions, quelques repéres. En Actas de forum UNESCO. IV Seminario Internacional. Vol. III, 313-315.

FALCÓN. R. M. (2010). Sentido del proyecto aefectivo. Tesis Doctoral dirigida por Begoña Simón. Universidad de Barcelona.

FONTAL, O. (2003). La educación patrimonial: teoría y práctica para el aula, el museo e internet. Gijón: Trea. - (2004). Introducción. El patrimonio: una realidad con muchas miradas. En R. CALAF Y O. FONTAL (Coords.), Comunicación educativa del patrimonio: referentes, modelos y ejemplos (17-19). Gijón: Trea.

- (2008). La importancia de la dimensión humana en la didáctica del patrimonio. En S. M. MATEOS (Ed.), La comunicación global del patrimonio cultural (79-110). Gijón: Trea.

- (2012). Patrimonio y educación. Una relación por consolidar. Aula de innovación educativa, 208, 10-13.

- (2013). Estirando hasta dar la vuelta al concepto de patrimonio. En O. FONTAL (Coord.), La educación patrimonial: del patrimonio a las personas (9-22). Gijón: Trea.

FONTAL, O.; DARRÁS, B y RICKENMANN, R. (2008). El acceso al patrimonio cultural. Retos y Debates. 
Pamplona: Universidad Pública de Navarra y Cátedra Jorge Otiza.

FONTAL, O. y MARÍN, S. (2011). Enfoques y modelos de educación patrimonial en programas significativos de OEPE. Educación artística: revista de investigación, 2, 91-96.

FONTAL, O. y MARÍN, S. (2014). La educación patrimonial en España: necesidades y expectativas para la próxima década. Revista de Patrimonio Histórico, 85. Recuperado de: http://www.iaph.es/revistaph/index.php/revistaph/article/ view/3442/3422\#.U_XFgSjEVDk

FONTAL, O. y JUANOLA, R. (2015). Heritage Education: a useful and profitable discipline within the cultural heritage management. Revista Cadmo. Giornale Italiano di Pedagogia sperimentale. An International Journal of Educational Research, XXIII, (1), 7-25.

GÓMEZ-REDONDO, C. (2011). Procesos de patrimonialización en el arte contemporáneo. Educación artística: revista de investigación, 2, 108-112.

- (2012a). Identización: la construcción discursiva del individuo. Arte, Individuo y Sociedad, 23 (2), 19-28.

- (2012b). Patrimonio e identidad: la educación patrimonial como vínculo entre individuo y entorno. En Actas I Congreso Internacional de Educación Patrimonial: Mirando a Europa: estado de la cuestión y expectativas de futuro: Madrid, 15, 16, 17 y 18 de octubre. Madrid:
Ministerio de Educación, Cultura y Deporte, 15-22.

HERNÁNDEZ, F. (2002): El patrimonio cultural: la memoria recuperada. Trea, Gijón.

MARÍN, S. (2013). Una investigación para abordar y entender nuestro patrimonio desde la perspectiva de la diversidad. Pulso: Revista de investigación, 36, 115-132. Recuperado de http://revistapulso.cardenalcisneros. es/documentos/articulos/165.pdf

LEY 16/1985 de Patrimonio Histórico Español. Boletín Oficial del Estado, 29 de Junio de 1985, num. 155, 20342-20352.

LLULL, J. (2005). Evolución del concepto y de la significación social del patrimonio cultural. Arte, Individuo y Sociedad, 17, 175-204.

LÓPEZ, E. (1987). La evaluación de programas. Papeles del psicólogo: revista del Colegio Oficial de Psicólogos, 31.

PÉREZ, S. (2013). Interpatrimonios: relaciones e interrelaciones en/con la educación patrimonial. En O. FONTAL (Coord.), La educación patrimonial: del patrimonio a las personas (57-72). Gijón: Trea.

PRATS, LL. (2004). Antropología y patrimonio. Barcelona: Ariel.

PRATS, J. (2001). Valorar el patrimonio histórico desde la educación: factores para una mejor utilización de los bienes patrimoniales. Aspectos didácticos de las ciencias sociales, 15,157 171. 
RODRIGO, M. (2009). La identidad como patchwork. IC. Revista científica de información y comunicación, (6), 285-305.

STAKE, R. E. (2006). Evaluación comprensiva y evaluación basada en estándares. Barcelona: Graó.

- (2006b). Multiple Case Study Analysis. NY: Guilford Press.
TORREGROSA, A. Y FALCÓN, R. M. (2013). Patrimonios instintivos. En R. HUERTA Y R. DE LA CALLE (coords.), Patrimonios migrantes (125-132). Valencia: Universitat de València.

UNESCO (2003). Texto de la convención para la Salvaguarda del Patrimonio Cultural Inmaterial. París: UNESCO. 